\title{
Overtone Singing: a surpreendente habilidade de perceber e emitir vocalmente uma série harmônica
}

\author{
GEOVANNI BORDIANO \\ LIDIA BECKER
}

Geovanni Bordiano é fonoaudiólogo pela Universidade Federal do Rio de Janeiro -UFRJ, com CRFa 1-1504, atua na área de saúde mental infanto-juvenil (CAPSI de Paracambi) e colabora em pesquisas interdisciplinares que buscam as relações entre a Fonoaudiologia e a Música. AFILIAÇÃO: Universidade Federal do Rio de Janeiro-UFRJ

Lidia Becker é Fonoaudióloga, Especialista em Voz pelo CFFa, Professora Adjunta do Departamento de Fonoaudiologia da Universidade Federal do Rio de Janeiro -UFRJ, com mestrado e doutorado pelo Programa de Pós-Graduação em Artes Cênicas, da Universidade Federal do Estado do Rio de Janeiro- UNIRIO. Supervisora do Ambulatório de Voz do Hospital Clementino Fraga Filho - UFRJ atua na assistência à população que apresenta alterações vocais, e no treinamento de profissionais da voz. Colabora em pesquisas sobre a voz e suas relações multidisciplinares com o Teatro e Música.

AFILIAÇÃO: Universidade Federal do Rio de Janeiro-UFRJ 


\begin{abstract}
RESUMO
O presente artigo objetivou compreender o conjunto de técnicas de canto mais popularmente conhecidas no Ocidente como "Overtone Singing", onde um único vocalista parece ser capaz de emitir dois ou mais sons distintos e simultâneos. Através de uma perspectiva etnomusical, fisiológica e acústica, busca-se entender as origens desse fenômeno artístico, bem como o funcionamento da máquina humana no que tange a sua produção. Assim, unem-se ciência e arte pela compreensão holística dos processos imbuídos nessa manifestação cultural tão singular. Para tanto, foi realizada uma revisão bibliográfica sobre o tema nas bases de dados SciELO e Biblioteca Virtual em Saúde (BVS) através de onze descritores a ele relacionados, além da utilização de conteúdo audiovisual presente no YouTube. Concluiu-se tratarse de uma manifestação artística que consiste em uma única emissão vocal, em que o vocalista sustenta uma nota fundamental e amplifica, através da ressonância do trato vocal, um harmônico de sua escolha. Fica claro, também, pela escassez de trabalhos, que o tema é, ainda, muito pouco pesquisado.
\end{abstract}

\title{
PALAVRAS-CHAVE
}

Voz, fonoaudiologia, Overtone Singing, cauda harmônica, canto.

\section{ABSTRACT}

The present article aimed to understand the technique of singing most popularly known in the West as "Overtone Singing", where a single vocalist seems to be able to produce more than one distinct and simultaneous sounds. Through an ethnomusical, physiological and acoustic perspective, we seek to understand the origins of this artistic phenomenon, as well as the functioning of the human machine in what concerns its production. Thus, science and art are united aiming a holistic understanding of the processes imbued in this unique cultural manifestation. This article presents a bibliographic review on the subject in the databases SciELO and Biblioteca Virtual em Saúde (BVS) through eleven descriptors related to it, in addition to the use of audiovisual content present on YouTube. We concluded that the artistic manifestation consists of a single vocal emission, in which the vocalist supports a fundamental note and amplifies, through the resonance of the vocal tract, other harmonics of his choice. Due to the scarcity of papers we also conclude that the theme remains under-researched.

\section{KEYWORDS}

Voice, speech-language therapy, Overtone Singing, harmonic, singing. 


\section{Introdução}

\subsection{Overtone Singing e suas origens}

O âmago da questão está na constante transformação da forma: na vida nada existe sem forma. A todo instante somos forçados a procurar a forma. Mas devemos ter em mente que essa forma pode ser um obstáculo total à vida, que não tem forma em si mesmo. Não há como escapar dessa dificuldade, e a batalha é permanente - a forma é necessária, mas não é tudo (BROOK, 1994, p.45).

Tal como os monges do Tibet, que passam anos a confeccionar belas paisagens em areias coloridas, para depois soltá-las ao vento, a efemeridade da forma viva nas artes é uma questão contemporânea que se aplica aos conceitos de construção e demolição. Segundo Brook, todo o processo de preparação é feito para ser jogado fora, num eterno construir para demolir (BROOK, 2008). Todo sopro de vida tem forma: "Nascer é assumir uma forma, quer se trate de um ser humano, de uma palavra ou de um gesto" (BROOK, 2008) - ao que acrescentamos, ou de um som.

O conjunto de técnicas de produção vocal aqui abordados recebe mais popularmente a denominação de "Overtone Singing", que consiste em uma forma singular de produção musical vocal em que um único vocalista parece emitir dois ou mais sons distintos simultaneamente: um mais grave e outro, mais agudo.

Sua prática fascinante tem, sem dúvida, uma origem profundamente cultural. Assim, esta expressão artística tão singular e recentemente divulgada no mundo ocidental tem despertado grande curiosidade e profundos questionamentos aos ouvidos menos familiarizados.

Todavia, a fim de entendermos a prática sob uma perspectiva holística, devemos ter em mente que essa é produto de uma rica expressão cultural e, ao mesmo tempo, um artefato da voz humana.

De acordo com Levin e Edgerton (1999), o Khöömei ou Khoomii (significando "garganta" na língua mongolesa, e que aqui chamaremos de Overtone Singing) nasce associado à antiga crença do Animismo, na prática do pastoreio nas vastas paisagens de Tuva, uma república autônoma da Rússia em sua fronteira com a Mongólia. A crença, assim, pressupõe a existência de alma ou poder espiritual em toda a natureza. A espiritualidade está imbuída em tudo que os cercam: rios, montanhas e toda a natureza. O espiritual se encontra nos elementos naturais e animais, como também nos sons por eles produzidos: seja no borbulhar de águas, no canto de um pássaro, na marcha de um cavalo. Dessa forma, acredita-se que o primeiro throat-singer (como são chamados os executores das técnicas) tenha surgido na tentativa de assimilar tal espiritualidade através da reprodução dos sons ouvidos.

$\mathrm{Na}$ cultura de Tuva, a prática do throat-singing é tão natural quanto a fala, pela emulação dos sons ambientes, de forma que as técnicas não são ensinadas formalmente, como a música, mas adquirida como uma língua. Desse modo, um grande percentual de pastores é capaz de realizar a técnica, embora nem todos consigam dominá-la plenamente (LEVIN E EDGERTON, 1999).

A popularidade da técnica entre os pastores tuvanos parece ter nascido da convergência entre dois fatores: cultura e geografia - presentes na sensibilidade do Animismo às sutilezas dos sons, sobretudo aos diferentes timbres e na habilidade 
de ressaltar e projetar harmônicos pela paisagem aberta da fauna tuvana de Estepe (LEVIN E EDGERTON, 1999).

As práticas mais notáveis das técnicas de throat-singing (ou Overtone Singing) são encontradas em Tuva e na região das Montanhas de Altai, na Mongólia. Mas técnicas similares também podem ser ouvidas em diferentes partes da Ásia Central (BLOOTHOOFT ET AL., 1992).

Dentre os Bashkirs, povo de língua turcomana das Montanhas de Ural, músicos cantam melodias com harmônicos intensificados pela respiração, em um estilo conhecido por uzliau. Cantores no Uzbequistão, Caracalpaquistão e Cazaquistão introduzem notas de harmônicos com maior intensidade na recitação de poesia. Certas formas de canto budista tibetano produzem um único harmônico reforçado e sustentado sobre um outro tom. Fora da Ásia, o uso de overtones na música tradicional é raro, embora não seja desconhecido. Ele ocorre, por exemplo, no canto das mulheres do Xhosa, na África do Sul (LEVIN E EDGERTON, 1999).

Todavia, a forma como esses cantores amplificam os harmônicos e suas propriedades acústicas foi pouco documentada na literatura atual. Apesar de ser uma técnica de raízes etnomusicais muito fortes dentre os povos supracitados, o uso das técnicas conhecidas popularmente como "Overtone Singing" tem adquirido grande popularidade no Ocidente nas últimas décadas, implicando, inevitavelmente, na tentativa de aprendizado, utilização e ensino da mesma, o que nos desperta a curiosidade de entender melhor esse fenômeno acústico e artístico-cultural.

\subsection{Fisiologia da produção vocal}

A fonoaudiologia é uma das ciências que estuda o fenômeno da voz humana: como ele nasce na passagem do ar expiratório pelas pregas vocais, gerando uma primeira onda sonora, de formato senoidal que, através de um processo natural da física acústica, vai se desdobrando à passagem pelo trato vocal. Praticamente todo som que ouvimos é formado por ondas de compressão e rarefação de ar, ondas chamadas complexas, que se propagam a partir de uma fonte sonora (MENEZES E HYPPOLITO, 2015). Os sons são, desse modo, produtos de um complexo sistema físico acústico. Tenhamos em mente que a maioria dos sons, salvas específicas exceções, são formados por um conjunto de frequências que, na voz humana e em instrumentos musicais, produzem um conjunto de características específicas e individualizadas que nos permite a distinção no meio de outros sons, a essa possibilidade de distinção dos sons denominamos "timbre".

Cada tom ou frequência decorrente destes desdobramentos é chamado de harmônico e compõe a unidade sonora que identificamos ao ouvir uma nota de piano, ou de outro instrumento musical. As emissões vocais na fala e no canto expressam o que se poderia denominar de "acorde", ou seja, um somatório de harmônicos que se agregam progressivamente, à medida em que se dá cada emissão. Portanto, ao se ouvir uma voz humana, ouve-se o timbre ou a qualidade vocal de cada indivíduo, que correspondente a determinada série harmônica.

A voz falada se expressa através de uma faixa média de frequências que está intimamente relacionada com o corpo do falante, sua postura, seu processo respiratório e sua capacidade de ressonância, de articulação e de projeção vocal. A 
voz cantada se expressa através de faixas de frequência mais maleáveis, com uma demanda mais exigente em termos de emissão vocal sendo, porém, igualmente, um somatório de harmônicos ou de notas musicais, que o ouvido humano percebe como um conjunto unificado. Entretanto, ainda que não identificáveis isoladamente, esses harmônicos ressoam fisicamente, tanto no trato vocal quanto no espaço exterior e são audíveis pelo ouvido humano.

Algumas técnicas de canto, em função de razões de origem cultural, exploram esse fenômeno de ressonância da voz humana e conseguem emitir notas individualizadas destas séries harmônicas, como ocorre no Overtone Singing.

Os eventos da fisiologia e da física acústica que culminam na produção vocal se iniciam com a adução das pregas vocais, gerando aumento da pressão infraglótica por conta do fluxo do ar expiratório. A resistência de adução das pregas vocais deve ser vencida pela pressão aérea do fluxo expiratório. Entra em ação, no momento em que a resistência glótica é vencida e as pregas vocais entram em abdução, o Efeito de Bernoulli - um fenômeno físico - o movimento da onda mucosa que produz a frequência fundamental da voz e sustenta a emissão vocal, através do comando nervoso periférico e central que inerva a musculatura intrínseca das pregas vocais à adução (COLTON, CASPER E LEONARD, 2009).

O controle da intensidade vocal é dado pelo fluxo expiratório e pela força de adução das pregas vocais. Quanto maior a força e o fluxo aéreo, maior a intensidade. Já o controle de frequência está intimamente relacionado ao grau de estiramento ou encurtamento das pregas vocais, sob ação primária da musculatura intrínseca da laringe, com origem e inserção na própria laringe, mais especificamente os músculos Cricotireoideo (CT) nas emissões mais agudas e, nas emissões mais graves, o Tireoaritenoideo (TA). Durante a ação do músculo Cricotireoideo as pregas vocais sofrem um estiramento que leva a uma diminuição da massa de mucosa vibrante, o que torna a voz mais aguda. O contrário é verdadeiro para a ação do músculo Tireoaritenoideo (TA), que aumenta a massa de mucosa vibrante durante o fluxo aéreo. Além disso, entram em ação, também, durante o controle de frequência da emissão vocal, o encurtamento e o alongamento do trato vocal, sob ação da musculatura extrínseca da laringe, de forma que na emissão de agudos, a laringe se encontra mais elevada, e o trato vocal mais encurtado, favorecendo a ressonância aguda, enquanto que na emissão grave, a laringe se encontra mais rebaixada, com trato vocal mais alongado, favorecendo a ressonância agravada (COLTON, CASPER E LEONARD, 2009) - sucessão de eventos que se explica pela Teoria Mioelástica-Aerodinâmica, proposta por Van Den Berg em 1954 (BEHLAU, 2001).

\subsection{Modelo Fonte-Filtro de produção vocal}

Segundo a concepção do Modelo Fonte-Filtro, a voz é fruto da integração equilibrada e funcional entre as cavidades de ressonância do corpo, sobretudo da face, e da emissão vocal. Este conceito se faz essencial à compreensão do tema proposto, uma vez que se trata de um fenômeno que, à primeira vista, parece inteiramente dependente do trato vocal - ou "filtro". (BEHLAU, 2001; PINHO, 2008)

$\mathrm{Na}$ imagem abaixo (Figura 1) se observa bem o modelo Fonte-Filtro. Segundo Levin e Edgerton (1999), a Fonte é responsável por produzir uma gama de 
harmônicos que são mais intensos em baixas frequências do que nas altas, enquanto o Filtro, composto pelo trato vocal, é responsável por transmitir os harmônicos que melhor se alinham com a frequência fundamental produzida, também denominada de "primeiro harmônico". Por fim, a radiação característica é composta pelo ar, que também modifica as ondas sonoras, agindo como um filtro secundário. A conjunção destes elementos traz como resultado a completude da voz humana.

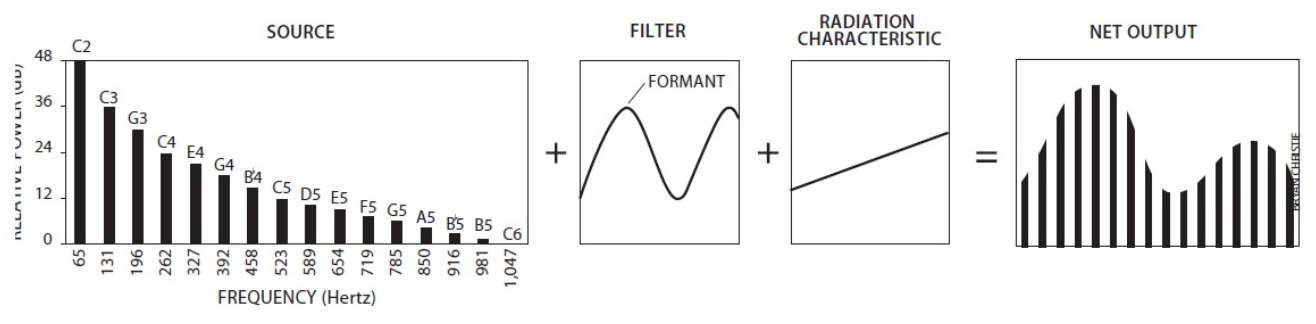

Figura 1. Modelo Fonte- Filtro explicitando a relação entre frequências tonais, Fonte, Filtro e onda complexa resultante dessas interações. Extraído de Levin e Edgerton (1999).

\subsection{Cavidades de ressonância da voz}

Na imagem seguinte (Figura 2) se observa a representação anatômica dos principais componentes do trato vocal e suas cavidades de ressonância. Dessa forma, após a produção de uma frequência fundamental na Laringe, o som gerado ressoa, isto é, se amplifica e se modifica ao se propagar pela Faringe, Cavidade Nasal, Alvéolos e toda cavidade oral, principalmente, além dos Seios Faciais não representados na imagem, dando o colorido da voz. Ressalta-se que a ressonância é um conceito de extrema importância para as artes vocais (LEVIN E EDGERTON, 1999).

Para entendermos esse fenômeno tão importante para definir a qualidade vocal do indivíduo, precisamos entender que ele depende do comportamento das ondas de vibração sonora dentro de tubos. Dadas as características de um sistema de tubo fechado, onde a pressão na extremidade livre se iguala à pressão atmosférica, e a pressão na outra extremidade é máxima, forma-se uma frequência natural (FN) no sistema, o que significa dizer que existe uma onda cujo comprimento meIhor se encaixa dentro deste tubo, sendo quatro vezes maior que o sistema. A ressonância ocorre, então, quando um sistema externo vibra na mesma frequência que a frequência natural do sistema de tubos (MENEZES E HYPPOLITO, 2015).

$\mathrm{Na}$ anatomia humana a laringe é considerada um tubo fechado. Neste tipo de sistema de tubos fechados dois processos físicos ocorrem: a ressonância e a interferência. A ressonância resulta da superposição de ondas idênticas de direções opostas: uma que incide e outra que está sendo refletida. Esta interferência entre as ondas idênticas gera uma onda complexa igual às duas originais, porém com maior amplitude - ou intensidade, em se tratando do som. Neste caso, os harmônicos gerados serão múltiplos ímpares da frequência natural do sistema (MENEZES E HYPPOLITO, 2015). 


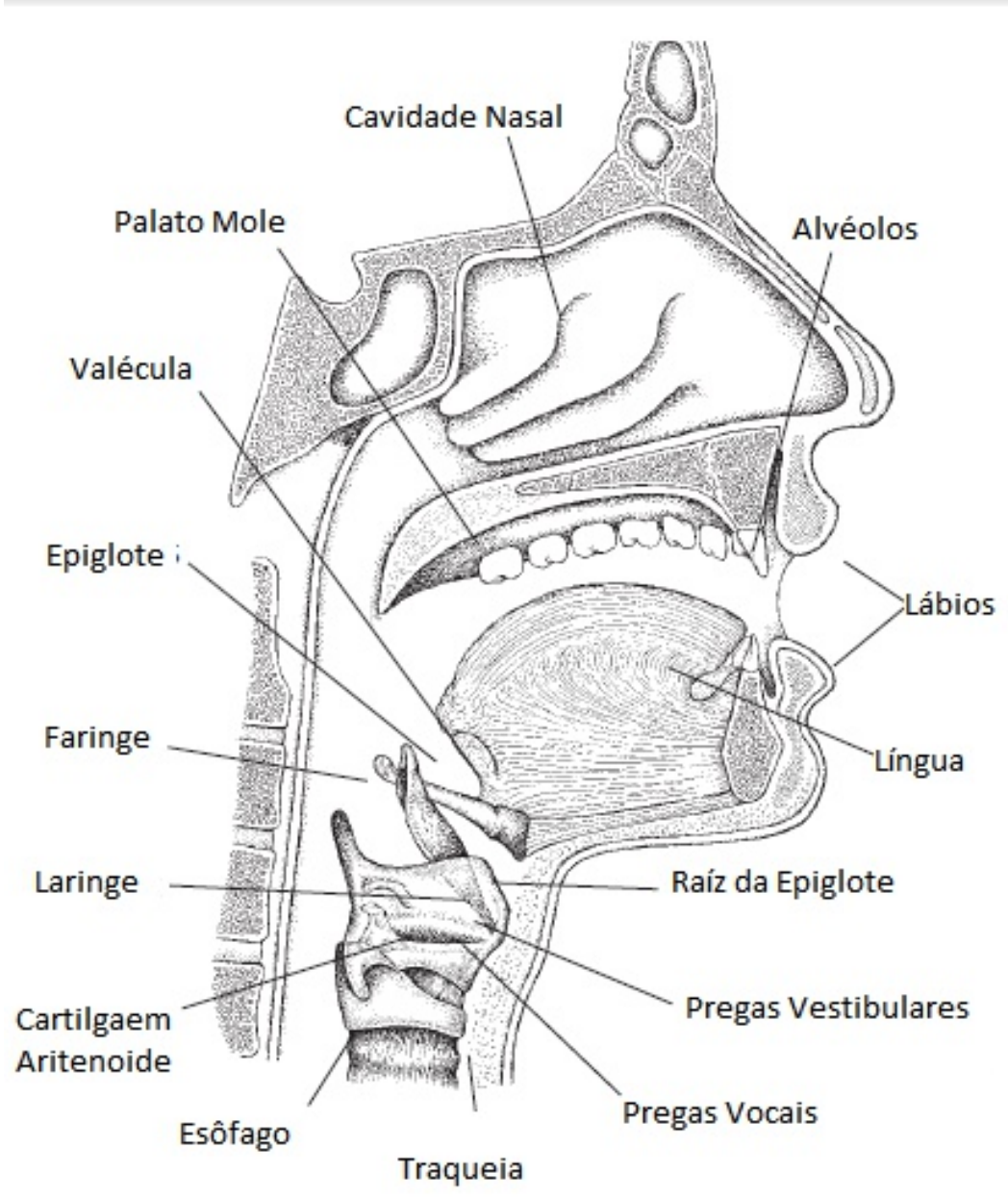

Figura 2. Corte sagital da cabeça e do pescoço. Adaptada de Levin e Edgerton (1999).

\subsection{Aspectos acústicos e cauda harmônica}

As ondas sonoras são compreendidas como vibrações mecânicas que se propagam em meios materiais, sejam sólidos, líquidos ou gasosos, e por essa relação de dependência de um meio de propagação são classificadas como mecânicas. Estas vibrações provocam perturbações no meio em que estão se propagando, causando a compressão de algumas regiões e deixando outras mais rarefeitas, em detrimento, considerando a pressão natural ou movimento natural das partículas deste meio. Quando estas ondas são compostas por um único movimento de compressão e rarefação, ou movimento simples, são chamadas de ondas senoidais, a exemplo dos tons puros gerados por audiômetros ou diapasões. Quando compostas por dois ou mais movimentos de compressão e rarefação, tornam-se ondas de movimento complexo, ou ondas complexas, a exemplo da voz humana e dos sons gerados por instrumentos musicais, como uma nota de um piano (MENEZES E HYPPOLITO, 2015). 
Quanto à propagação das ondas sonoras, devemos considerar que a massa e a elasticidade do meio de propagação são características que definem a velocidade de propagação e a atenuação da vibração acústica, embora existam outros fatores que também influenciam esta propagação (MENEZES E HYPPOLITO, 2015).

Quando duas ou mais senoides se somam para formar uma onda complexa, a onda resultante mantém uma relação harmônica com as senoides que a constituem. Logo, os harmônicos são sons presentes nas ondas sonoras complexas, gerados pelos múltiplos das senoides que as compõem, sendo a inicial dentre essas chamada de "frequência fundamental" (F0) - também conhecida por "primeiro harmônico" - , enquanto as demais, que são múltiplos dessa frequência fundamental compreendem os harmônicos (F1, F2, F3, etc). A cada vez que a senoide se desdobra em novos harmônicos, ocorre um fenômeno denominado pela teoria musical de "cauda harmônica", que forma uma série de oito sons, conhecidos como uma oitava. Assim, uma frequência de $500 \mathrm{~Hz}$ está uma oitava acima de $250 \mathrm{~Hz}$ (MENEZES E HYPPOLITO, 2015).

$\mathrm{Na}$ imagem abaixo (Figura 3 ) temos a representação em notação musical e em Hertz de uma frequência fundamental e seus harmônicos, aplicados ao Overtone Singing.

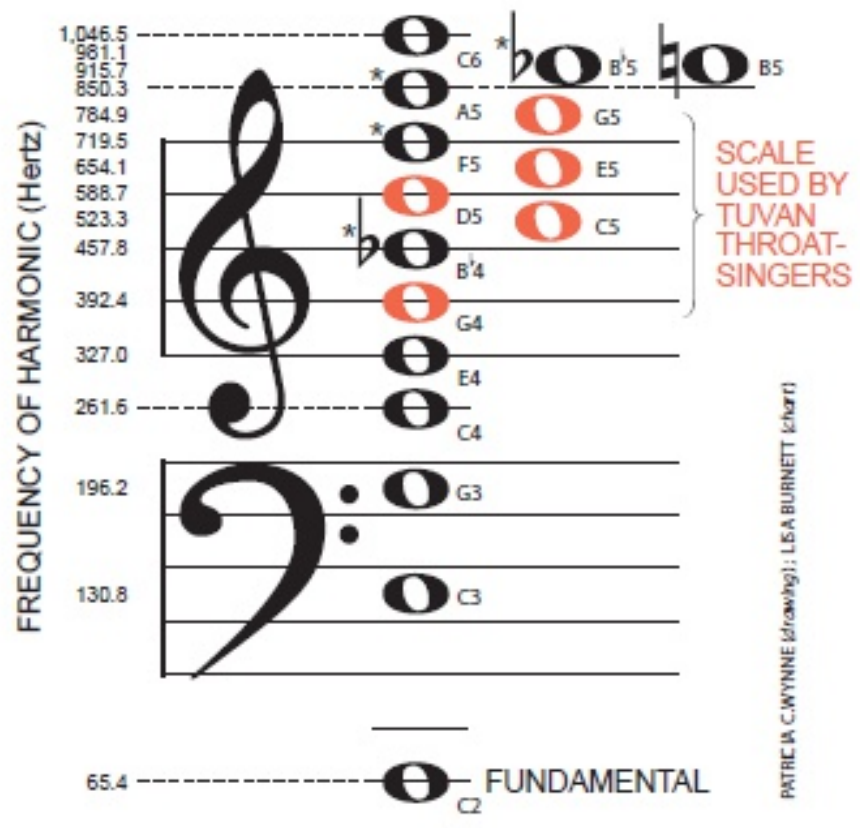

Figura 3. Representação musical de uma frequência fundamental e sua escala harmônica. Extraído de Levin e Edgerton (1999). 


\subsection{Conceitos aplicados ao Overtone Singing}

Tomemos como exemplo prático e visual dos aspectos acústicos envolvidos na prática do Overtone Singing, as explicações contidas em vídeos publicados na rede de compartilhamento de vídeos YouTube, propostas pela musicista alemã e Overtone Singer expoente na atualidade chamada Anna-Maria Hefele. A artista domina as técnicas e tem desenvolvido novas formas de ensiná-las a entusiastas do mundo ocidental, fascinados por sua singularidade e complexidade sonora. Entre essas técnicas, que utilizam tecnologia de ponta em sua análise, apontamos um software capaz de captar e representar graficamente toda a série harmônica gerada a partir de uma única emissão vocal, com ou sem uso das técnicas do Overtone Singing, como mostrado nas imagens a seguir (Figuras 4 e 5).

Em um de seus vídeos, intitulado "Polyphonic overtone singing - explained visually", Hefele explica a representação gráfica da cauda harmônica através do software denominado de "Overtone Analyzer."

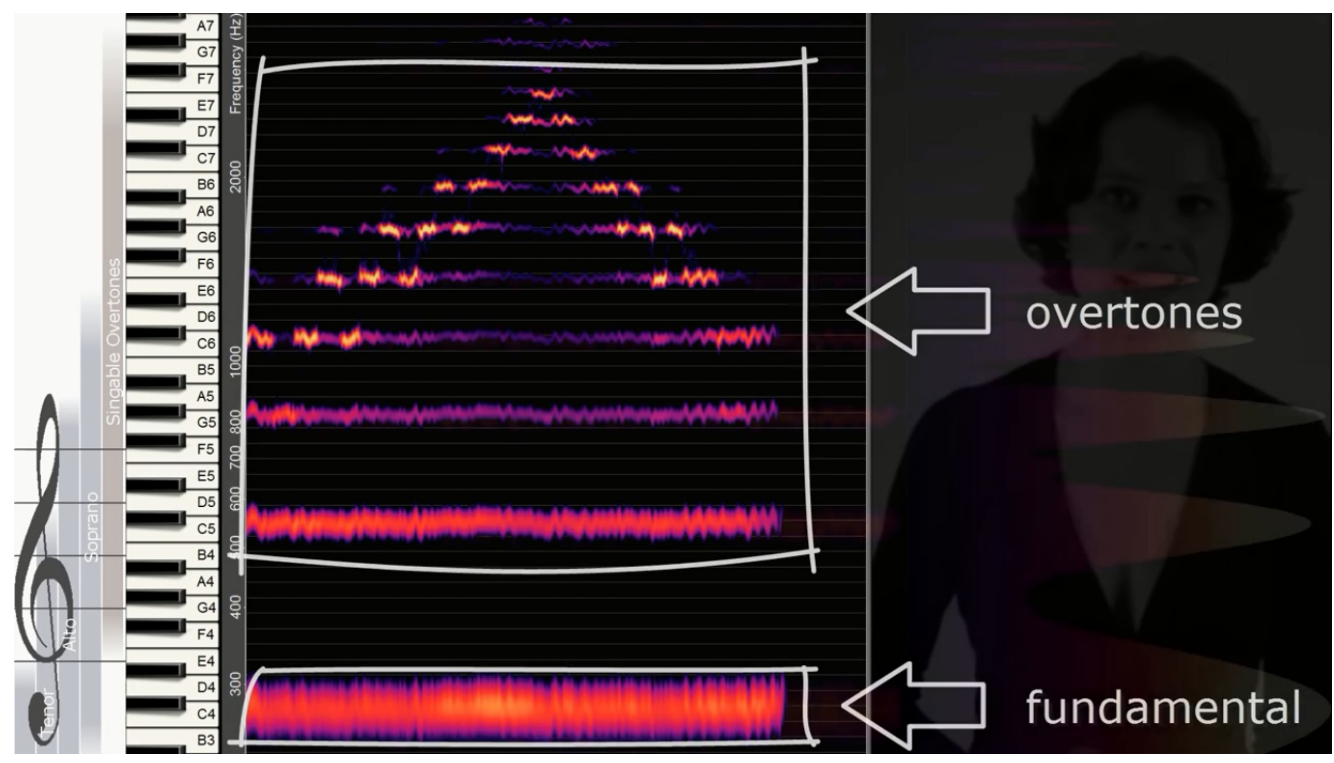

Figura 4. Espectrograma mostrando a frequência fundamental em C4 e seus harmônicos. Extraído de YouTube (2014).

Através desse software, é possível observar graficamente (Figura 4) a emissão de uma frequência fundamental sustentada em C4 (Dó 4) e uma faixa de ao menos 9 harmônicos sobrepostos à frequência fundamental (os overtones). Observa-se, também, que o segundo harmônico - ou segundo formante-, situado em C5 (Dó 5), situa-se uma oitava acima da frequência fundamental - ou primeiro harmônico/formante-, novamente, situado em C4 (Dó 4) e assim sucessivamente. 


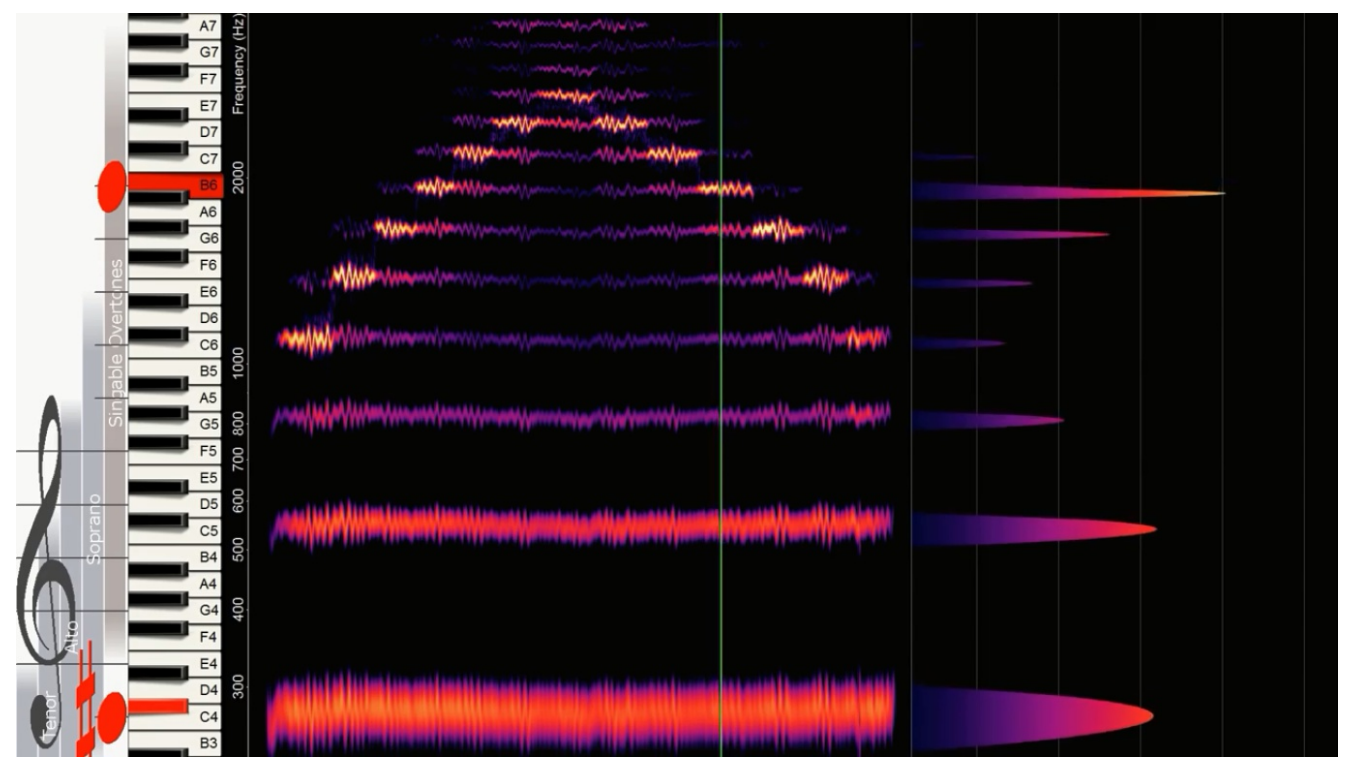

Figura 5. Relação dos harmônicos (à esquerda) com a intensidade (à direita), extraído de YouTube (2014).

$\mathrm{Na}$ imagem acima (Figura 5), as notas em vermelho na escala de piano utilizada para a representação gráfica do som vocal mostram a frequência fundamental sendo emitida em C\#4 - Dó 4 sustenido), junto ao harmônico selecionado pela cantora para o ganho em intensidade, que, por sua vez, é medida na parte direita da imagem, mostrando que a frequência fundamental e o sétimo harmônico, situado em B6 (Si 6) são os mais audíveis naquele momento, em detrimentos de todos os outros harmônicos presentes causando a sensação de audibilidade de dois tons sendo emitidos simultaneamente por um único cantor.

Dessa forma, tornam-se claros os desdobramentos que compõem a cauda harmônica. Ainda, a possibilidade de visualizar tais desdobramentos se faz prova científica imprescindível a serviço da arte, ao mesmo tempo que define a imperiosa necessidade de desenvolvimento de saberes multidisciplinares.

\section{Objetivos}

\subsection{Objetivo Geral}

Sob uma perspectiva holística, buscar conhecimentos científicos básicos sobre a fisiologia da produção vocal que permitam embasar o entendimento do fenômeno Overtone Singing e podem ser de grande utilidade a uma enorme gama de profissionais da voz e afins.

\subsection{Objetivo Específico}


Entender as produções artísticas conhecidas como Overtone Singing, observando a fisiologia e a acústica do fenômeno, bem como seu caráter etnomusical.

\section{Métodos}

O presente artigo consiste em uma revisão bibliográfica no âmbito da fonoaudiologia sobre o tema Overtone Singing. Para tanto, foram pesquisados artigos nas bases de dados SciELO e Biblioteca Virtual em Saúde (BVS) através dos descritores "Canto Harmônico"; "Canto Polifônico"; "Canto Mongol"; "Canto Difônico"; "Overtone Singing"; "Throat Singing"; "Mongolian Singing"; "Harmonic Chant"; "Harmonic Singing"; "Kargyraa" e "Sygyt", sem a utilização de nenhum filtro nas pesquisas. No total, foram encontrados 99 artigos nas línguas inglesa e portuguesa. Os resumos da bibliografia encontrada foram lidos e então utilizados apenas os trabalhos que faziam relação direta com o tema do presente estudo, ou que se relacionavam à voz profissional, mais especificamente ao canto, fazendo uma relação indireta ao tema, sendo excluídos os demais trabalhos. Após a aplicação do critério de exclusão restaram, em total, apenas 5 artigos diretamente relacionados ao tema, publicados entre 1992 a 2004 e 11 trabalhos indiretamente relacionados, sendo 10 artigos e uma tese de mestrado, publicados entre 1977 e 2015.

Além dos artigos e da tese de Mestrado, a fim de embasar teoricamente assuntos tangentes ao tema proposto e, assim, facilitar a compreensão do mesmo, foram utilizados, também, 6 livros, e 1 vídeo do YouTube.

\section{Resultados da pesquisa bibliográfica}

Os resultados da pesquisa bibliográfica nas bases de dados, bem como os critérios de inclusão e de exclusão podem ser representados nas seguintes tabelas (Tabelas 1 e 2):

\begin{tabular}{|c|c|}
\hline \multicolumn{2}{|c|}{ Critérios de Inclusão } \\
\hline $\begin{array}{c}\text { Trabalhos diretamente relacionados com } \\
\text { o tema }\end{array}$ & 5 \\
\hline $\begin{array}{c}\text { Trabalhos indiretamente relacionados } \\
\text { com o tema }\end{array}$ & 10 \\
\hline
\end{tabular}

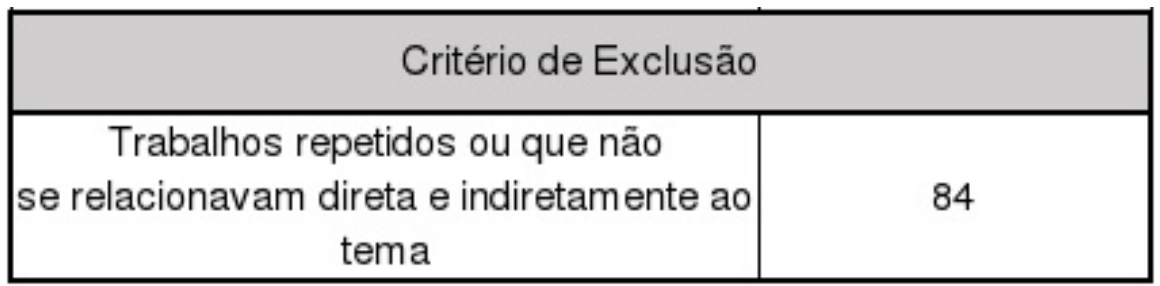

Tabela 1.Quantidade de trabalhos utilizados e excluídos de acordo com os critérios de inclusão e de exclusão.

ouvirouver Uberlândia v. 14 n. 2 p. 466-480 jul. |dez. 2018 


\begin{tabular}{|c|c|c|}
\hline Descritores & $\begin{array}{c}\text { Resultados - base de dados } \\
\text { BVS }\end{array}$ & $\begin{array}{c}\text { Resultados - base de } \\
\text { dados } \\
\text { SciELO }\end{array}$ \\
\hline Canto harmônico & 0 & 0 \\
\hline Canto polifônico & 0 & 0 \\
\hline Canto mongol & 0 & 0 \\
\hline Canto difônico & 0 & 0 \\
\hline Overtone singing & 3 & 6 \\
\hline Throat singing & 43 & 0 \\
\hline Mongolian singing & 3 & 0 \\
\hline Harmonic chant & 9 & 3 \\
\hline Harmonic singing & 32 & 0 \\
\hline Kargyraa & 0 & 99 \\
\hline Sygyt & 90 & 0 \\
\hline Total & 0 & 0 \\
\hline Total Geral & 0 & 0 \\
\hline Quantide de & 0 & 0 \\
\hline
\end{tabular}

Tabela 2. Quantidade de trabalhos encontrados por descritores pesquisados nas bases de dados.

\section{Discussão: Overtone Singing - a execução das técnicas}

Segundo Levin e Edgerton (1999), o Overtone Singing consiste em uma técnica de canto onde o vocalista produz dois ou mais tons distintos simultaneamente a partir de uma única emissão vocal. Um dos tons ouvidos apresenta frequência mais grave em relação ao segundo, que estará sempre situado em uma frequência mais aguda. O tom mais grave é essencialmente uma frequência fundamental sustentada, enquanto o tom mais agudo é produto de uma série harmônica, amplificado em detrimento dos demais harmônicos presentes naturalmente na voz humana.

Bloothooft et al. (1992), em um estudo de base acústica e perceptoauditiva do Overtone Singing, realizado com um cantor experiente nesta técnica, relatam que o som resultante desta possui características de uma escala musical, uma vez que os tons mais agudos se sucedem à uma frequência fundamental, concluindo, por este fato, que estes tons mais agudos são harmônicos desta primeira frequência fundamental - ou primeiro harmônico. 
Uma vez que os harmônicos são frequências com relação de múltiplos de uma fundamental, os harmônicos que se sucedem a uma fundamental C3 (Dó 3 $130.8 \mathrm{~Hz}$ ), por exemplo, serão as múltiplas desta frequência, C4 (Dó $4-261.3 \mathrm{~Hz}$ ) e assim por diante. Os harmônicos, portanto, possuem uma relação matemática com seu som gerador (F0, ou primeiro harmônico). Dessa forma, na execução do Overtone Singing, a emissão de uma frequência fundamental, qualquer que seja, levará a uma gama distinta e específica de harmônicos correspondentes a ela. Contudo, um mesmo harmônico pode ser entendido como fruto de frequência fundamentais diferentes. Na prática, temos que um harmônico que soe em C6 (Dó $6-1046.5 \mathrm{~Hz}$ ) é, ao mesmo tempo, o quarto harmônico de C4 (Dó $4-261.6 \mathrm{~Hz}$ ) e o oitavo harmônico de C3 (Dó $3-130.8 \mathrm{~Hz}$ ). Para isso, é claro, o cantor necessita de um extremo domínio da técnica. Os autores concluem, através da análise acústica realizada no estudo que, para o sucesso da execução da técnica, é necessária uma emissão estável da frequência fundamental ( $F 0$ ) e relatam a presença de nasalização durante a execução. Quanto a análise perceptual, estes mesmos autores apontam para a existência de um mecanismo de percepção humana que desempenha um papel fundamental na técnica, possibilitando ao cantor perceber os sons emitidos e reconfigurar suas estruturas de emissão de forma apropriada a se obter os dois tons simultâneos característicos do Overtone Singing (BLOOTHOOFT et al.,1992).

Contudo, apesar das importantes considerações acerca do fenômeno, o trabalho não traz especificações sobre o subtipo da técnica de Overtone Singing utilizada pelo indivíduo.

Levin e Edgerton (1999), em um estudo amplo, de cunho etnomusical, acústico e fisiológico sobre o tema, relatam um estudo de imagens de vídeofluoroscopia de nove cantores, conduzido pelos Hospitais da Universidade de Wisconsin, com suporte do National Center of Voice and Speech, onde identificam ao menos três formas de execução da técnica (ou subtipos), as quais: o Sygyt; o Khöömei e o Kargyraa.

Durante a execução do Sygyt (que significa assobio), a ponta da língua se mantém atrás dos dentes incisivos centrais superiores, enquanto o meio da língua se movimenta cranial e caudalmente, de forma a entoar sucessivos harmônicos que ganham em intensidade. Adicionalmente, manipulam a abertura e forma dos lábios, de forma a evitar perda de energia (LEVIN E EDGERTON, 1999).

$\mathrm{Na}$ execução do Köömei, o cantor movimenta posteriormente a língua, o que culmina na produção das vogais / $\mathrm{u} / \mathrm{e} / \mathrm{i} /$, fazendo com que o primeiro formante caia e o segundo suba em intensidade. Controlando precisamente o decréscimo do primeiro formante e o ganho do segundo, o cantor, ao executar esta técnica, consegue tonar separadamente ambos harmônicos (LEVIN E EDGERTON, 1999).

No Kargyraa, os cantores controlam a abertura da boca calma e precisamente, além de encurtarem a laringe, de forma a aumentarem a frequência do primeiro formante e, dependendo desta frequência, são capazes de isolar do 12 o ao $42^{\circ}$ formante. Neste estilo, a execução é feita, também, através da vibração das pregas vestibulares (ou falsas pregas vocais) (LEVIN E EDGERTON, 1999).

Apesar dos estudos sobre a produção do Overtone Singing em diferentes estilos, os mecanismos de execução das técnicas não são, ainda, bem compreendidos e tendem a cair em explicações fisiologicamente vagas. 
Apesar disso, Bloothooft et al. (1992) e Levin e Edgerton (1999) entram em concordância ao apontarem a existência de mecanismos de biofeedback no que tange a propriocepção do cantor durante a execução das técnicas, permitindo a este o controle dos tons e da série harmônica que está sendo produzida, além de admitirem a evidente distorção do trato vocal durante as emissões. O principal mecanismo de biofeedback hipotetizado é a sensação de vibração retroflexa semeIhante a que ocorre na técnica fonoterápica dos Tubos Finlandeses, embora outros mecanismos tão importantes quanto estejam relacionados. Dessa forma, ao emitir uma frequência fundamental e exercer determinados movimentos de língua, as ondas sonoras são refletidas, retornando ao local de origem, sendo então amplificadas - pensa-se aqui no mecanismo físico de ressonância, onde duas ondas idênticas em frequência se sobrepõem formando uma onda complexa igual, mas de maior intensidade. Essa sensação sonora permite distinguir os harmônicos amplificados da frequência fundamental e, associada à propriocepção da conformação do trato vocal no momento em que se obtém o resultado desejado, parecem ser as peças fundamentais à possibilidade de execução do Overtone Singing.

\section{Considerações finais}

Embora sua origem nos remeta a períodos ancestrais, o fenômeno do Overtone Singing é um artefato da voz humana ainda pouco estudado, e seus mecanismos fisiológicos ainda pouco esclarecidos. O presente estudo, porém, permitiu esclarecer que a aparente emissão múltipla e simultânea de sons ouvidos não provém de duas fontes sonoras distintas, mas de uma única fonte glótica e que a emissão vocal e simultânea dos desdobramentos ressonantais depende essencialmente da habilidade do cantor em manipular os seus órgãos fonoarticulatórios, particularmente, os movimentos da língua, e da sua percepção auditiva, capaz de perceber os sons presente na cauda harmônica. A conclusão mais importante para a fonoaudiologia, em específico para a área da voz, refere-se à importância do trato vocal como aparato fisiológico da ressonância e suas possibilidades criativas enquanto ferramenta a serviço da ciência, da arte e expressividade.

Conclui-se que o entendimento do tema requer conhecimento aprofundado sobre o fenômeno sonoro musical e entendimento sólido sobre o funcionamento do sistema anatomofisiológico de emissão e de ressonância da voz humana, revelando-se como tema multidisciplinar que propõe unir arte e investigação científica, que possa influenciar positivamente os cantores em sua performance artística e a ciência fonoaudiológica em sua prática clínica.

\section{Referências}

BEHLAU, M. Voz: O livro do Espec'ialista. vol 1. São Paulo: Revinter, 2001

BLOOTHOOFT, G. et al. Acoustics and perception of overtone singing. The Journal Of The Acoustical Society Of America, [s.I.], v. 92, n. 4, p.1827-1836, 1992. Acoustical Society of America (ASA). Disponível em < http://asa.scitation.org/doi/pdf/10.1121/1.403839> Acesso: 12 mar. 2018 
BROOK, P. A porta aberta. Reflexões sobre a interpretação e o teatro. Tradução de Antonio Mercado. Rio de Janeiro: Civilização Brasileira, 2008.

BROOK, P. Ponto de Mudança. Rio de Janeiro: Civilização Brasileira, 1994.

COLTON, RH; CASPER, JK; LEONARD. Compreendendo os problemas da voz. 3. ed. São Paulo: Revinter, 2009. $445 \mathrm{p}$.

HEFELE, AM. Disponível em <https://www.youtube.com/watch?v=UHTF1-IhuC0> Acesso: 12 mar. 2018.

LEVIN, TC.; EDGERTON, ME. The Throat Singers of Tuva. Sci Am, [s.I.], v. 281, n. 3, p.80-87, set. 1999. Nature Publishing Group. Disponível em < http://www.uvm.edu/ outreach/ThroatSingingArticle.pdf> Acesso: 12 mar. 2018

MENEZES, PL; HYPPOLITO, MA. Biofísica da Audição e Bases para a Audiologia. In: BOÉCHAT, Edilene Marchini et al. Tratado de Audiologia. 2. ed. Rio de Janeiro: Guanabara Koogan, 2015. Cap. 5. p. 30-35.

PINHO, S; PONTES, P. Músculos intrínsecos da laringe e dinâmica vocal: Série Desvendando os Segredos da Voz. vol 1. Rio de Janeiro: Revinter, 2008.

Recebido em 20/03/2018 - Aprovado em 29/10/2018

Como citar:

BORDIANO, Geovanni; BECKER, Lidia; SCHAMBECK. Overtone Singing: a surpreendente habilidade de perceber e emitir vocalmente uma série harmônica. ouvirOUver; Uberlândia, v.14,n.2, p.466-480, jul./dez. 2018. Disponível em: http://www.seer.ufu.br/index.php/ouvirouver; DOI:http://doi.org/10.14393/OUV23v14n2a2018-15 